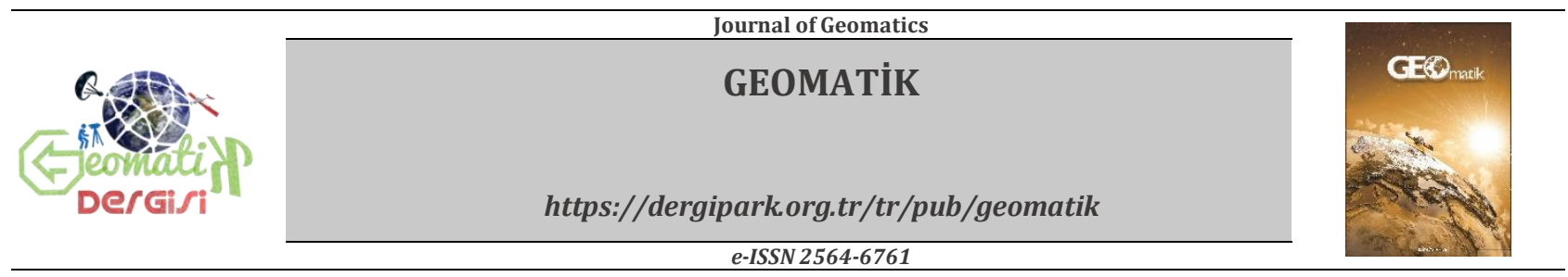

\title{
Yersel lazer tarama yöntemi ile farklı geometrik yapıdaki özelliklerin modellenmesi
}

\author{
Lütfiye Karasaka ${ }^{* 1}$, Adin Adnan Rashid Beg ${ }^{2}$ \\ ${ }^{1}$ Konya Teknik Üniversitesi, Mühendislik ve Doğa Bilimleri Fakültesi, Harita Mühendisliği Bölümü, Konya, Türkiye \\ ${ }^{2}$ Konya Teknik Üniversitesi, Lisansüstü Eğitim Enstitüsü, Konya, Türkiye
}

\author{
Anahtar Kelimeler \\ Yersel lazer tarama \\ Ölçme \\ Modelleme \\ Nokta bulutu
}

\begin{abstract}
ÖZ
Lazer tarama teknolojisi optik-mekanik bir ölçme tekniğidir. Lazer tarama ile obje ve yakın çevresinin çok kısa sürede üç boyutlu konum bilgileri elde edilir. Alıcı ile nesne arasındaki mesafe ise bir elektromanyetik enerji olan lazer ışının seyahat süresi ile belirlenmektedir. Lidar tekonolojisi olarak ifade edilen bu ölçme yöntemi günümüzde farklı platformlarda yersel lazer tarama, mobil lazer tarama ve havadan lazer tarama olarak karşımıza çıkarak mekâna veya nesnelere ait 3B veri ediniminde hızlı ve doğru çözümler sunmaktadır. Günümüzde yersel lazer tarama teknolojisinin; mimari belgeleme, arkeolojik çalışmalar, 3B modelleme, madencilik çalıșmaları, deformasyon analizleri, orman envanterlerinin çıkarılması gibi çeşitli mühendislik uygulamalarında kullanılması ile farklı mühendislik problemleri daha kolay çözüme ulașabilmektedir. Ayrıca lazer tarama teknolojisi karmaşık sahnelerin yoğun nokta bulutları yoluyla hızlı bir şekilde yeniden oluşturulmasını sağlar. Bu anlamda kazaların veya adli suçların meydana geldiği karmaşık sahnelerin hızlı bir șekilde belgelenmesi, olay sonrası analizler için delil teşkil eden bilgilerin tespiti ve bunların sayısal arşivi içinde yersel lazer tarama bu görevi gerçekleștirebilen önemli bir araçtır. Bu çalışmada yersel lazer tarama ile farklı uygulamalar içinde yer alan farklı geometrik özellikteki yapılar modellenmiștir. Verilerin değerlendirilmesinde SCENE, 3DReshaper, JRC 3D Reconstructor yazılımları kullanılmıștır.
\end{abstract}

\section{Modeling of different geometrical properties by terrestrial laser scanning}

\author{
Keywords \\ Terrestrial laser scanning \\ Measurement \\ Modeling \\ Point cloud
}

\begin{abstract}
Laser scanning technology is an optical-mechanical measuring technique. By means of laser scanning, three-dimensional position information of the object and its immediate surroundings is obtained in a very short time. The distance between the receiver and the object is determined by the travel time of the laser beam, an electromagnetic energy. This measurement method, which is referred to as lidar technology, provides fast and accurate solutions for 3D data acquisition of space or objects by appearing as terrestrial laser scanning, mobile laser scanning and aerial laser scanning on different platforms. Today, terrestrial laser scanning technology; architectural documentation, archaeological studies, 3D modeling, mining studies, deformation analysis, forest inventories, such as the use of various engineering applications can be solved more easily with different engineering problems. In addition, laser scanning technology allows rapid reconstruction of complex scenes through dense point clouds. In this sense, the rapid documentation of complex scenes in which accidents or judicial offenses occur, the identification of evidence that constitutes evidence for post-incident analysis, and terrestrial laser scanning within their digital archive is an important tool to accomplish this task. In this study different geometric structures are modeled in different applications with terrestrial laser scanning. SCENE, 3DReshaper, JRC 3D Reconstructor software were used to evaluate the data.
\end{abstract}




\section{GíRiş}

1970'li yıllarda geliștirilen havadan ve yerden lazer tarama, LiDAR tekniği temeline dayanmaktadır. Açlımı "Líght Detection and Ranging" olan LiDAR, lazer darbeleri kullanarak bir nesne veya bir yüzeyin uzaklığını anlamaya yarayan bir teknolojidir. $\mathrm{Bu}$ tekniğin jeodezik aletlerde reflektörsüz mesafe ölçme yöntemi olarak kabul görmesi 1990'lı yıllara dayanmaktadır. İlk reflektörsüz total station, 1994 yılında Almanya'nın Ruhr Üniversitesinde geliştirilmiștir (Reshetyuk, 2006; Scherer, 2004). İlk ticari ve çalıştırılabilir yersel lazer tarayıcılar 1990 yılların sonlarına doğru geliştirilmiştir. Yersel lazer tarama geleneksel ölçme teknikleri ile kıyaslandığında 3B nokta bilgilerin çok yüksek hızla elde edilebildiği bir ölçme tekniğidir. Nokta bulutlarının; kaydedilmesi, farklı yöntemler kullanılarak birleştirilmesi ve fazla nokta verilerinin silinebilmesi ile objelerin 3B modelleri oluşturulmaktadır. Yersel lazer tarayıcılarla elde edilen 3 boyutlu (3B) bilgi günümüzde pek çok mühendislik uygulamalarında farklı disiplinler tarafından kullanılmaktadır. Söz konusu uygulama alanlarını 3B şehir modelleme çalışmaları, endüstriyel ortamların, mega fabrikaların modellenmesi deformasyon izleme çalışmaları, kesit, alan ve hacim hesaplamaları, mimari yapıları ve arkeolojik eserleri belgeleme çalışmalar olarak örneklendirilebilir (Ergün, 2011; Gümüş, 2007).

Özellikle Son yıllarda ülkemizde tarihi ve kültürel varlıkların 3 boyutlu modellenmesi çalışmalarında yersel lazer tarama sistemlerinin kullanımı giderek yaygınlaşmaktadır. Yersel lazer tarama teknolojisi ile taranması düşünülen objeler küçük yapılar olabildiği gibi geniş, büyük ve karmaşık geometrili yapılar da olabilirler. Yersel lazer tarama verilerinin sivil mühendislik ve haritalama projelerinde yaygın olarak kullanıldığı pek çok uygulama vardır (Kushwaha ve ark. 2020; Perc, M. ve Topolšek, D.; 2020; Wieczorek, T. ve ark. 2018).

\section{YÖNTEM}

Lazer tarama, bir yüzeyin LiDAR (Light Detection and Ranging) teknolojisi kullanılarak örneklendiği veya tarandığı bir yöntemdir. Lazer ışını olarak ifade edilen optik kaynak aracılığı ile lazer tarama cihazı ve obje arasındaki mesafe belirlenebilmektedir. Lazer ışınını normal ışıktan ayıran özellikleri (tek renklilik, uyumluluk, ıraksama, yönlendirilebilirlik, yansıma, yoğunluk) sayesinde gerçek dünya veya nesnelerin şekli ve boyutu ile ilgili veriler kolaylıkla toplanıp analiz edilebilmektedir. Lazer tarayıcılar tarama mekanizması olarak da bilinen optik aynalar aracılığı ile lazer ışınının yatay ve düşey yönlerde yönlendirilmesi ile ilgili objenin veya yüzeyin taramasını yapar. Bir lazer tarayıcının lazer ışınını yatay ve düşey yönlerde saptırma kapasitesi teknik bilgilerinde görüş açısı olarak verilir. Bir objenin üç boyutlu modelini oluşturabilmek için farklı görüş açıları ile birden fazla tarama istasyonunun kullanılması gerekebilir. Tarama sonucunda elde edilen nihai ürün ölçme mesafesi ile orantılı olarak değișen milyonlarca noktadan oluşan nokta bulutudur. Nokta bulutu verisi, konum bilgisi, yoğunluk bilgisi (intesity), RGB değeri, tarama açısı, yansıma sayısı, yansıma boyu gibi bilgiler içerir. Lazer taramanın en önemli avantajı oldukça kısa bir sürede yoğun nokta konum bilgisini yüksek doğrulukla kaydedebilmesidir. Lazer tarama teknolojisi ile toplanan veriler çeşitli uygulamalar için kullanışlı olan sayısal, iki boyutlu çizimler veya üç boyutlu modeller oluşturmak için kullanılabilmektedir (Van Genechten 2008; Karasaka 2012).

Lidar (Light Detection and Ranging) teknolojisi hava ve yersel Lidar olmak üzere ikiye ayrılan geniş bir uygulama alanına sahiptir. Farklı uygulama alanları verilerin amacına, taranan alanın büyüklüğüne, istenilen ölçüm aralığına ve ekipmanın maliyetine dayalı olarak değişen özellikleri olan tarayıcılar gerektirirler (Vosselman ve Maas 2010). Sabit yersel tarama, gerçek bir zamanda sistematik bir sıklık içerisinde belirli bir bölgedeki bir obje yüzeyinin otomatik olarak 3 boyutlu koordinatlarını ölçen yer bazlı bir cihazın kullanımıdır.

Yersel Lidar teknolojisi birçok alanda kullanılmaktadır. Örneğin: mimarlık, arkeoloji, tarihi ve kültürel mirasın korunması, ormancılık ve çevresel uygulamalar, endüstri ve madencilik, adli tip ve sanal simülasyon gibi alanlardaki uygulamaları örnek olarak verilebilir (Yılmaz ve Yakar 2006).

\section{MATERYAL ve YÖNTEM}

Bu çalışmada yersel lazer tarama teknolojisinin farklı uygulamaları ve elde edilen verilerin farklı yazılımlarda değerlendirilmesi ele alınmıştır.

\subsection{FaroFocus 3D X 330 Yersel Lazer Tarayıcısı}

Çalışmada kullanılan FaroFocus 3D X 330, ayrıntılı ölçme ve belgeleme için kullanılan yüksek hızlı üç boyutlu bir lazer tarayıcıdır. Kompleks ortamların ve geometrilerin sadece birkaç dakika içinde son derece ayrıntılı üç boyutlu görüntülerini üretmek için lazer teknolojisini kullanmaktadır. Ortaya çıkan görüntüler milyonlarca $3 \mathrm{~B}$ görüntü noktasının birleştirilmesidir. Prensip olarak Focus 3D, döner aynanın merkezine kızılötesi lazer ışını göndermek suretiyle çalışmaktadır. Bu aletin döner aynası, lazer ışınını taranan çevrede saptırmaktadır. Çevredeki nesnelerden yayılan ışık daha sonra tarayıcıya geri yansıtılır (Şekil 1). 


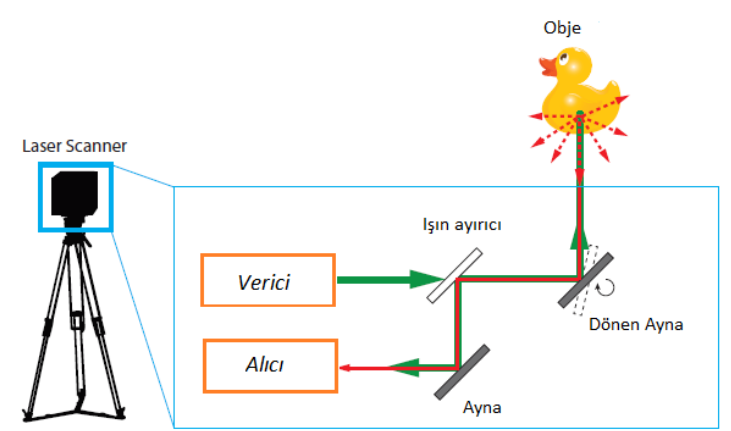

Şekil 1. Lazer ışınının saptırılması

Focus3D, mesafe ölçme yöntemi olarak, faz karşılaştırma yöntemi kullanmaktadır. Tarayıcı ile obje arasindaki mesafe lazer sinyalleri arasında faz farkları ölçülmek suretiyle belirlenmektedir. Faz farkı tabanlı tarayıcılar sürekli genlik modülasyonlu bir dalga yayar, bu modülasyon genellikle birkaç dalga boyunun kombinasyonu şeklindedir. Şekil 2.'de gösterildiği gibi bir nesneye olan mesafe yayılan sinyal ile alınan sinyal arasındaki faz kaymasının ölçülmesiyle belirlenir.

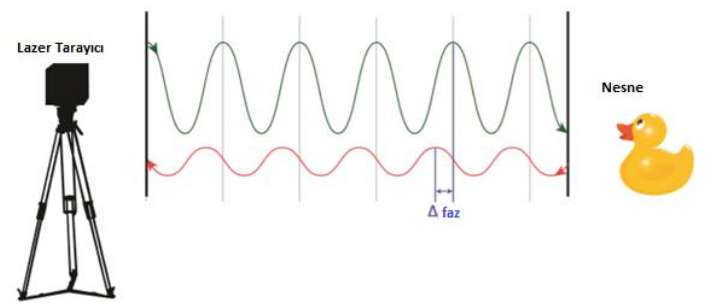

Şekil 2. Faz farkı mesafe ölçme yöntemi

$\Delta \mathrm{t}=\mathrm{tr}-\mathrm{te}$

psinyal $=\mathrm{c} \frac{t r-t e}{2}$

Yayılan sinyalin basit bir modülasyondan, yani bir dalga boyunu kullanan bir sinüzoidal sinyalden oluştuğunu varsayarsak, zaman farkı $\Delta \mathrm{t}$, yayılan ve alınan sinyal arasindaki farz farkı $\Delta \phi$ ve sinyal periyodu arasındaki faz farkı $\lambda$ / c ile ilişkilidir.

$\Delta \mathrm{t}=\frac{\Delta \phi}{2 \pi} \frac{\lambda}{\mathrm{c}}$

$R_{f a z}$ mesafesi (2.8) denkleminden elde edilir ve faz bazlı lazer tarayıcılar için (2.10) denklemi olarak tanımlanmıştır.

$$
\operatorname{Rfaz}=\frac{\Delta_{\varphi}}{4 \pi} \lambda
$$

Sinyal sinüzoidal olduğundan, faz farkının ölçümü belirsiz olabilir, yani ölçülen periyot sayısında bir belirsizlik olabileceği anlamına gelir. Bu belirsizliği önlemek için, genlik modülasyonu için çoklu dalga boyları kullanılır.

\subsection{Kullanılan Yazılımlar}

Scene; 3B Belgeleme yazılımı FARO Focus3D ve Freestyle3D için özel olarak tasarlanmıștır. SCENE otomatik nesne tanıma, tarama kayıtlama ve konumlandırma gibi özellikleri ile tarama verisini etkin ve basit bir şekilde işler ve yönetir.

3DReshaper; farklı uygulamalar için nokta bulutu işlemeye yarayan ve çok yönlü bir yazılımdır. $\mathrm{Bu}$ yazılım birçok 3B modelleme veya inceleme ihtiyaçlarını karşılamaktadır. Kolayca Mesh oluşturma, hacim hesaplama ve CAD uygulamaları özelikleri sayesinde 3B modelleme çalışmaları için vazgeçilmez bir yazılım haline gelmektedir (URL8).

JRC 3D Reconstructor; farklı kaynaklardan gelen nokta bulutlarını ve görüntülerini yöneten çok platformlu ve yüksek çözünürlüklü bir yazılımdır. JRC teknolojileri, güçlü LineUp aracı sayesinde otomatik hedefsiz (target-less) taramalar ve coğrafi referanslama için en iyi sonuçları verir (URL5).

\section{UYGULAMALAR}

Çalışmanın bu bölümünde Faro Focus 3D yersel lazer tarama cihazı ile gerçekleştirilen uygulamalar örneklenmiștir.

\subsection{YLT Endüstriyel Uygulama Örneği}

Lazer tarayıcılar, günümüzde endüstriyel uygulamalarda kullanılan en önemli ölçme aletleri arasında yerini almıştır. Diğer klasik ölçme ve fotogrametrik yöntemlerle kıyaslandığında, veri elde edilmesi ve değerlendirilmesinde hiz ve maliyet açısından üstünlükleri vardır. Lazer taramalar sonucu elde edilen, taranan objeye ait gerçeğe yakın gösterimini sunan 3 boyutlu nokta bulutlarından CAD yazılımlarında, 3 boyutlu modeller elde edilmektedir. $\mathrm{Bu}$ modeller üzerinden istenen bilgilere anında ulaşılabilmekte, böylece üretim sırasında ortaya çıkacak hatalara müdahale edilerek hatalar yok edilebilmektedir.

Endüstriyel uygulamaya kapsamında Mühendislik ve Doğa Bilimleri Fakültesi' nde bulunan bir havalandırma makinesi seçilmiştir. Detaylı bir obje olduğu için taramalar 11 farklı istasyondan gerçekleştirilmiştir.

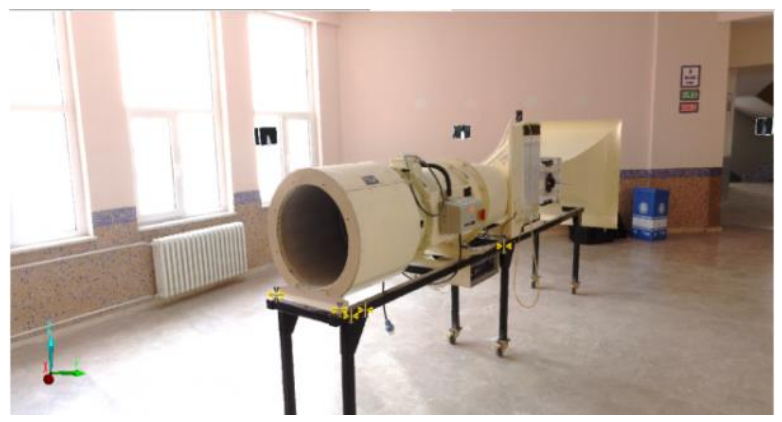

Şekil 3. Havalandırma makinası

Farklı oturumlardan elde edilen verilerin işlenmesi ve birleştirilmesi için Faro Scene 
yazılımının veri işleme (Process) aşamasına geçilmiştir. $\mathrm{Bu}$ adımda taramaları renklendirilme, yansıtma eșiği (reflectance threshold), mesafe filtresi (distance filter), hedef levhaları belirleme vb. seçenekleri kullanarak her bir oturum için taranan nokta bulutu elde edilmiştir.

Fotogrametri ve lazer tarama teknolojisi, düzgün geometrik şekli olmayan objelerin hacminin ve alanının hesaplanmasında tercih edilen yöntemlerdendir. 3B modeller üzerinden objeye ait matematiksel bilgiler kolaylıkla elde edilebilmektedir.

Havalandırma borusunun lazer tarama verileri Faro Scene 3D yazılımı ile veri işleme adımına geçilerek; birleştirme (registration), nokta bulutu oluşturma ve mesh aşamasından sonra seçilen kesitin alan ve hacmi hesaplanmıştır. Şekil 4 de havalandırma makinesinden alınan kesitin alanı $0.1936 \mathrm{~m}^{2}$, hacmi $0.1527 \mathrm{~m}^{3}$ olarak hesaplanmıştır.

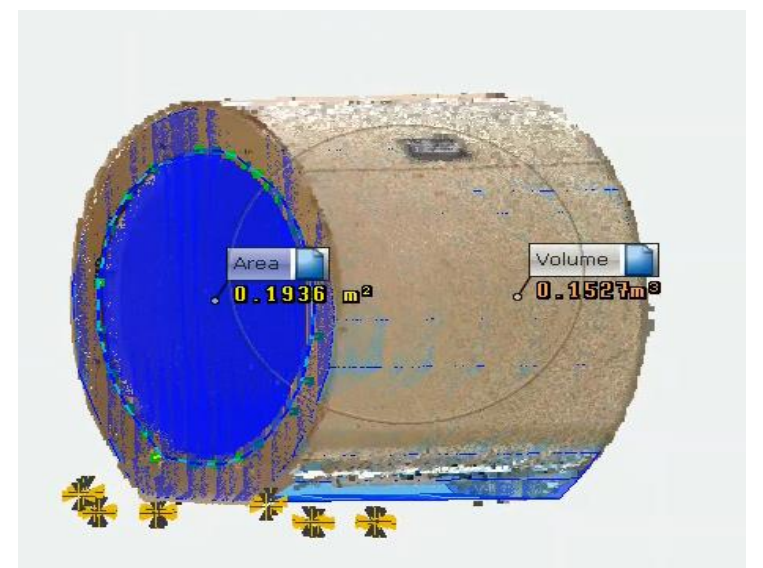

Şekil 4. Mesh oluşturma, alan ve hacim hesaplama

\subsection{YLT Cami Minaresi Uygulama Örneği}

Yersel lazer tarayıcılar, lazer ıșınını istenilen doğrultularda yatay ve düşey yönlerde saptırılabilmesi yeteneği ile farklı geometrik özellikteki objelerin ölçülmesinde büyük kolaylık sağlamaktadır. Nokta bulutu verisinden koni, küre gibi geometrik objelerin hacmini hesaplamak için cami minaresi yersel lazer tarayıcı ile taranmıștır.
Değerlendirme aşamasında Scene yazılımının koni veya küre gibi objelerin hacimlerini hesaplama konusunda yetersiz kalmasından dolayı minarenin koni şeklinde olan üst kısmının hacmini 3DReshaper yazılımı ile hesaplanmıştır. Minarenin koni şekilli bölümünün hacmi 3.609 m³$^{3}$ olarak ölçülmüştür.

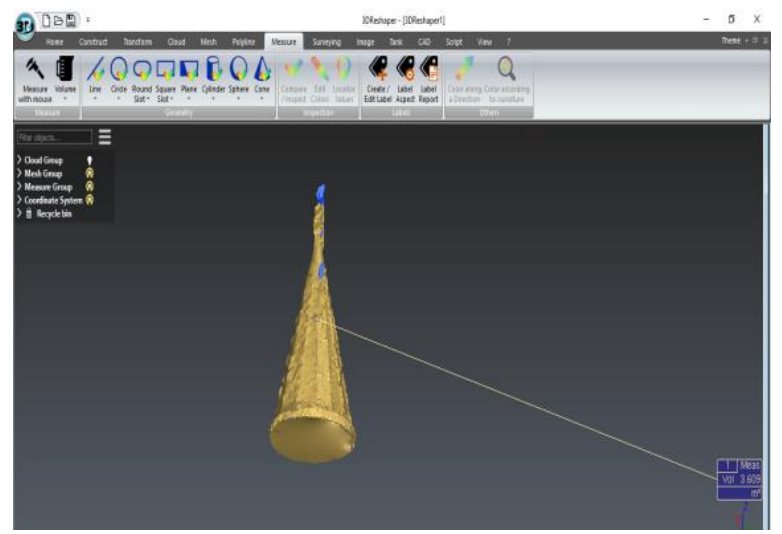

Şekil 5. Mesh ve hacim hesaplama

\subsection{YLT Madencilik Örneği}

Tünel veya madencilik uygulamalarında güvenlik önemli bir unsurdur. Yersel lazer tarama teknolojisi olası riskleri asgari düzeye indirmek, tehlike oluşturabilecek çatlakları, periyodik ölçümler ile belirlenen deformasyonları tespit etmek için kullanılabilir. Verilerin 3B dokümantasyonu ile gerekli güvenlik önlemleri önceden alınarak olası maden çökmesi gibi ciddi kazalar önlenebilir. Ayrıca lazer tarayıcılar sundukları veri potansiyeli ile hacim ve şekil gibi kritik geometrik bilgileri yakalarken gereksiz kazı çalışmalarının önüne geçerek iş maliyetini azaltmaya yardımcı olur. Bu uygulamada, tünelin hacmini ve kesitlerini elde etmek için Gexcel JRC 3D Reconstructor yazılımını kullandık. Şekil 6 da gösterildiği gibi tünelin hacmini belirleyebilmek için mesh oluşturduktan sonra istenilen mesafede ve sayıda için yatay ve düşey kesitler çıkardık. 1.767.306 adet üçgenden oluşturduğumuz mesh göre tünelin alanı 2090.232 $\mathrm{m}^{2}$ olarak, belirlediğimiz kesite göre hacmini ise $5911.383 \mathrm{~m}^{3}$ olarak hesapladık.

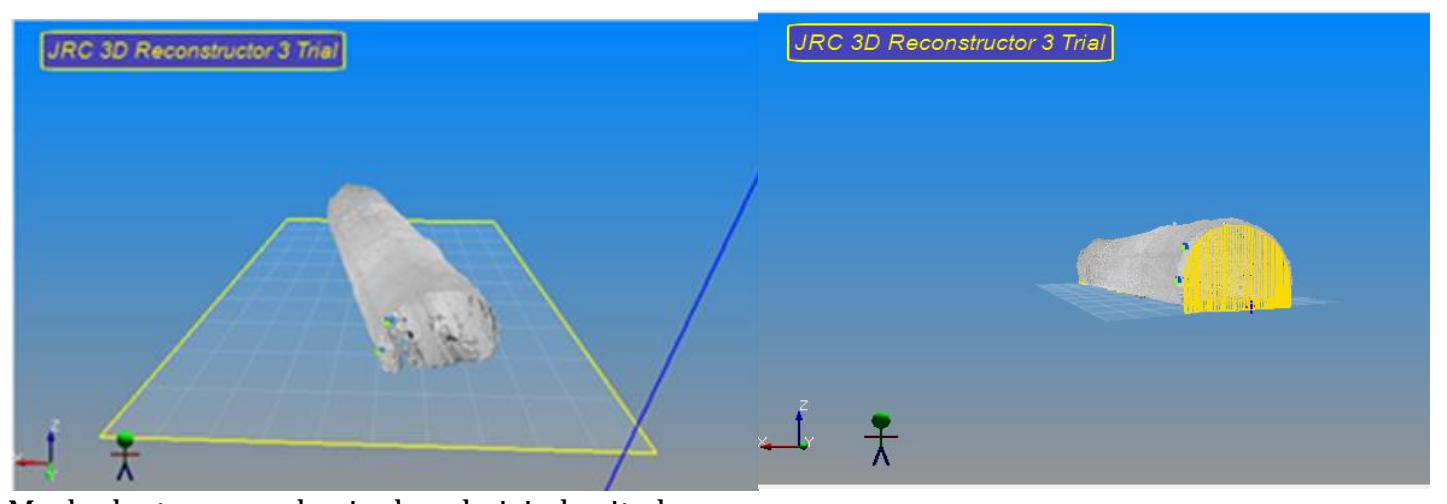

Şekil 6. Mesh oluşturma ve hacim hesabı için kesit alma 


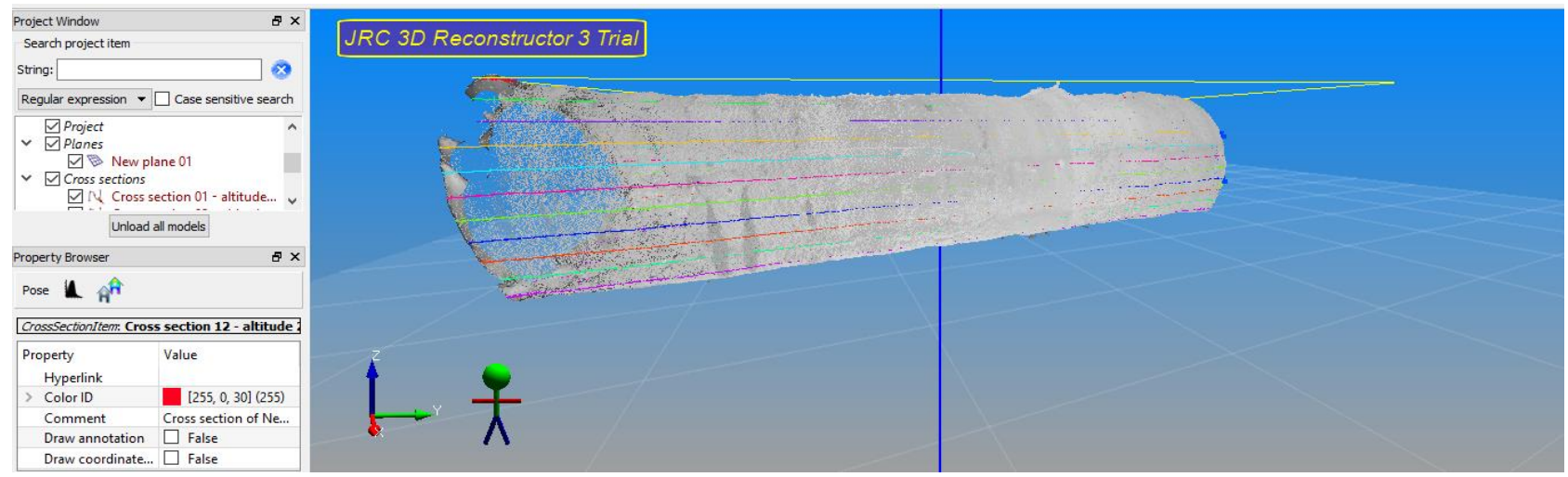

Şekil 7. Hacim hesaplama

\subsection{Tarihi Yapıların Modellenmesi-doğal Kaya Oluşumlu Sarnıç Örneği}

Yersel lazer tarama son yıllarda tarihi ve kültürel mirasın korunması ve belgelenmesine yönelik araştırma ve çalışmalarda sıklıkla kullanılan bir yöntem haline gelmiştir. Ayrıca eserin üç boyutlu modelinin diğer CAD yazılımlarına ve VRML gibi doku kaplama özelliğine sahip 3 boyutlu farklı veri formatlarına export edilebilmesi ile fotogrametrik teknikler farklı disiplinlere de hizmet etmektedir. Kilistra'nın kuzeybatısında yer alan Başpınar Sarnıcı, bölgedeki en büyük sarnıçtır. Düz olmayan dikdörtgen planlı sarnıç, zeminin seviyesi altında bir ana kaya oyularak yapılmıştır (Beg, 2018).

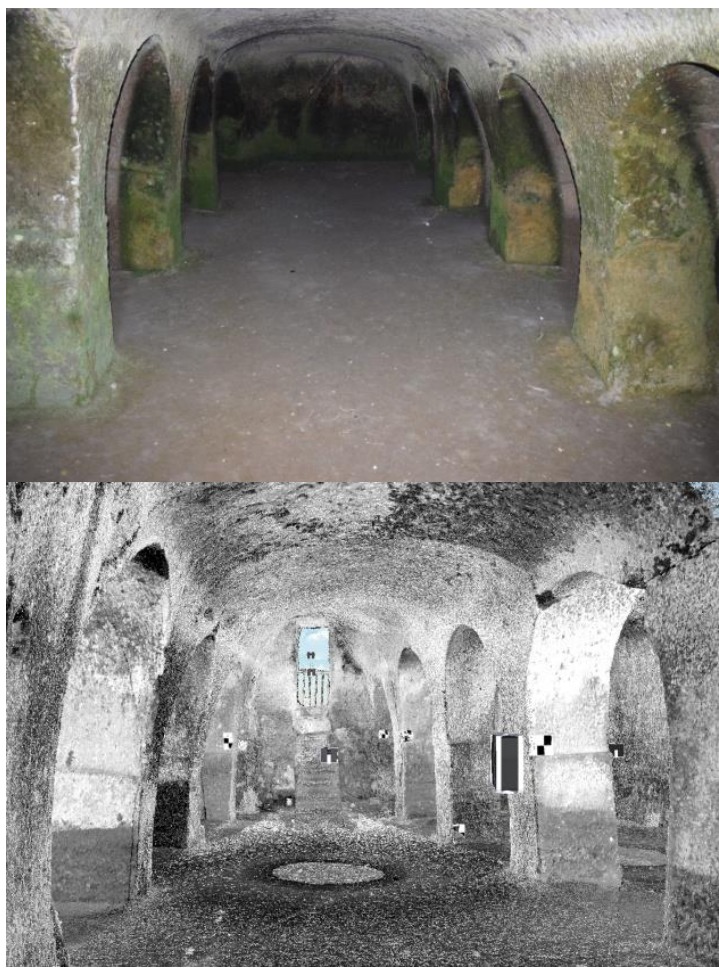

Şekil 8. Başpınar Sarnıcı ve nokta bulutu görseli

3B modeller elde edildikten sonra Faro Scene yazılımının DrawToAutoCAD uygulaması aracılığı ile ürettiğimiz 3B modellerin 2B çizimleri yapılmıştır. Elde edilen 2B çizimlerin üzerinden yapıların alanları ve çevreleri AutoCAD yazılımı kullanılarak hesaplanmıştır. Sarnıcın alanı $230.209 \mathrm{~m}^{2}$, çevresi
63.67 m olarak bulunmuştur. Başpınar Sarnıcının su depolama kapasitesi $163.074 \mathrm{~m}^{3}$ olarak hesaplanmıştır. Ayrıca sarnıcın kubbe hacmi 3DReashaper ile $1.993 \mathrm{~m}^{3}$ bulunmuştur (Beg, 2018).

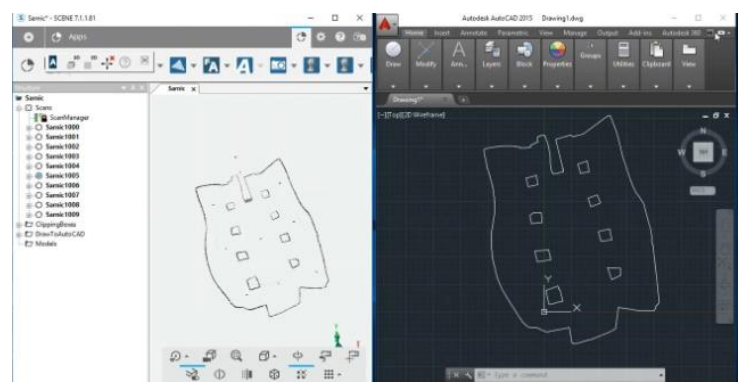

Şekil 9. Başpınar Sarnıcının AutoCAD ile çizimi

\subsection{Trafik Kazası Örneği- Hasarlı Araç Modelleme}

Yersel lazer tarayıcılar olay yerinin kaza sonrasına ait yüksek doğrulukta ayrıntılarını, oluşturulan 3B model üzerinden elde edilen metrik çözümler ile trafik kazaları araştırmaları için taşınabilir bir çözüm sunar. 3B lazer tarayıcılar ile toplanan yoğun veri farklı görüș açılarından analiz edilerek araç deformasyonu analizleri yapılabilir, gerçek olayın simüle edilebilmesi için kaza animasyonu hazırlanabilir.

Bu uygulamada kuramsal trafik kazası sahnesini arızalı bir araba kullanarak gerçekleștirdik. Oluşturulan 3B model üzerinde aracın kaza sonrası darbe aldığı yüzey ile çarptığı yüzey arasındaki mesafe değeri $1.3980 \mathrm{~m}$ olarak ölçülmüştür. Elde edilen veriler ile FaroSCENE yazılımı ile oluşturulan aracın ortofoto görünümü şekil 11 de verilmiştir.

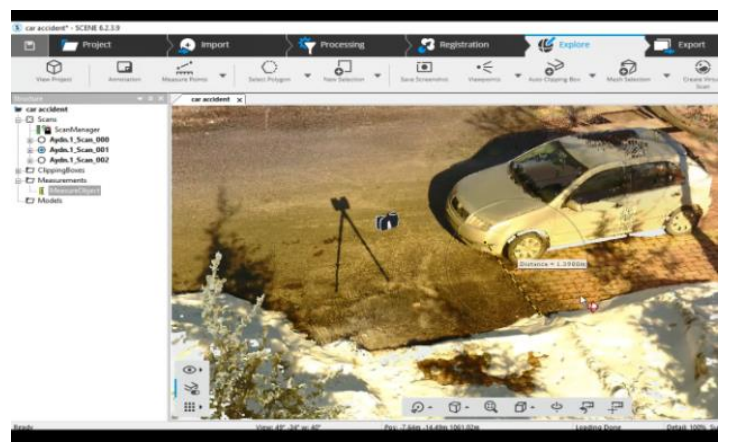

Şekil 10. Trafik kazası sahnesi 


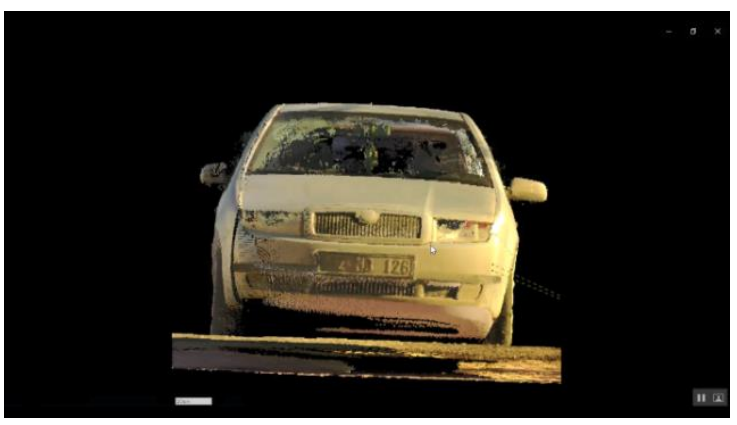

Şekil 11. Ortofoto görünümü

\subsection{Adli Vaka Sahnesi Örneği}

Bir suç işlendikten sonra olay yerinin bozulmaması ve delillerin kaybolmaması için çok kısa bir süre içerisinde acil adımlar atılması gerekir. Yersel lazer tarayıcılar sayesinde renkli görüntülerle birlikte ayrıntılı bir 3B nokta bulutu kaydederek olay yerini hızlı şekilde taramak suretiyle bu risk azaltılabilir. 3B adli tıp dokümantasyon sayesinde tüm olay yeri kayıt altına alınabilir. $\mathrm{Bu}$ belgeleme yöntemi olay yerinin istenilen perspektiflerden farklı görüş açılarının incelenmesine yardımcı olarak, mermi yolu ve siçrayan kan analizleri vb. delillerin dijital kayıtlar altında tutulmasında yardımcı olmaktadır. Değerlendirme yapan adli tıp uzmanları için zaman tasarrufu sağlamasının yanısıra daha doğru ve kaliteli sonuçlar elde etmesine yardımcı olur.

$\mathrm{Bu}$ uygulamada adli bir vakayı örnekleyen bir suç sahnesi yaratmak amacıyla 6*12 $\mathrm{m}^{2}$ alanlı bir odada 4 farklı istasyondan lazer tarama gerçekleştirdik. Taramadan sonra nokta bulutları ve uygulamanın 3B modeli oluşturmak için FaroSCENE yazılımını kullandık. Her bir taramayı ayrı ayrı process yaptıktan sonra 4 tarama verisini birleștirerek olay yerinin sahne görünümünü nokta bulutu olarak elde ettik (Şekil 13). Manüel birleştirme sonuçlarına göre; en az \% 81.9 bindirme oranı ve $0.6 \mathrm{~mm}$ doğruluk hatası ile tek bir nokta bulutu verisi oluşturduk.

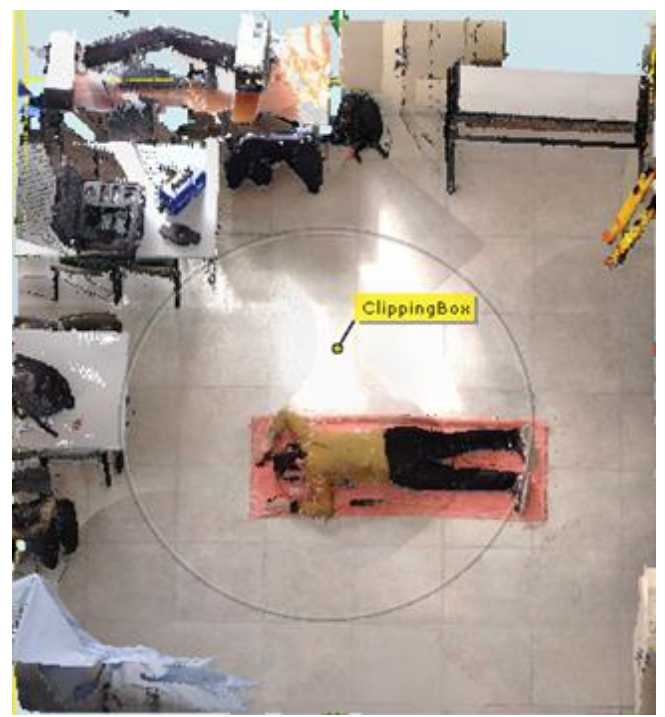

Şekil 12. Nokta bulutu sahne görünümü

\section{SONUÇLAR ve TARTIŞMA}

Son yıllarda hızla gelișen lazer tarama teknolojisinin güçlü, pratik, doğru, güvenilir çözümler sunması yönüyle birçok uygulama için kabul edilebilir ve kullanılabilir bir değerlendirme aracı olmuştur. Tarama işlemi sonucunda mesafe ve 3B nokta konum bilgisinin yanı sira, tarama verilerinin yazılımlarla birleștirilmesi ile sahne görünümünü veren $3 \mathrm{~B}$ modellerde elde edilmektedir. Veri boyutunun çok büyük olduğu detaylı objelerin veya karmaşık sahnelerin daha hızlı modellenerek doğru ve güvenilir geometrik ve metrik bilgilere ulaşılmasında yersel lazer tarama tekniğini klasik ölçme yöntemlerine göre büyük avantaj sağlamaktadır. Özellikle mühendislik alanında zaman, maliyet ve emek açısından önemli bir yer tutan lazer tarama yönteminin kullanımı giderek yaygınlaşmaktadır.

Çalışma kapsamında farklı boyutlarda farklı geometriye sahip nesnelerin modellenmesi, metrik bilgilerinin çıkartılmasının yanı sıra vaka olaylarının yeniden canlandırılmasında yersel lazer tarama verilerinin kullanabilirliği farklı yazılımlar kullanılarak araştırılmıştır. Uygulamada elde edilen veriler SCENE, 3DReshaper, JRC 3D Reconstructor yazılımları kullanılarak değerlendirilmiştir.

FAR0 Focus3D lazer tarayıcısı için özel geliştirilen SCENE yazılımı tarama verisini etkin ve basit bir şekilde işler ve yönetmesi ile dikkat çekmektedir. Faro Scene yazılımının DrawToAutoCAD aracılığı ile 2B çizimler yapabilmesi yani AutoCAD yazılımı ile eş zamanlı çalışabilmesi aynı zamanda alan, çevre uzunluğu gibi bilgileri kolaylıkla çıkarılabilmesi ise bu yazılımın üstün yanlarını ortaya koymaktadır. Ancak sadece düzgün geometrik yapıların (dikdörtgenler prizması, silindir, vb.) hacimlerini hesaplayabilmekte ve bozuk geometrideki objelere ait hesaplamaları yapamamaktadır. Değerlendirme aşamasında SCENE yazılımının koni veya küre gibi objelerin hacimlerini hesaplama konusunda yetersiz kalmasından dolayı minare gibi koni şekline sahip geometrik yapılarda 3DReshaper yazılımı kullanılmıştır. Başpınar Sarnıcının kubbesinin hacim hesaplaması için 3DReashaper, su depolama kapasitesini hesaplamak için de JRC 3D Reconstructor yazılımları kullanılmıştır. Kubbenin 3B modeli 3DReashaper yazılımına aktarıldıktan sonra 3B bir mesh oluşturularak kubbenin hacmi bulunmuştur.

Tarama verilerinin birleștirildiği diğer bir yazılım JRC 3D Reconstructor yazılımıdır. Bu yazılım hem düzgün hem de bozuk objelerin hacim hesabını yapabilmektedir. JRC 3D Reconstructor yazılımı, Faro Scene yazılımina kiyasla daha fazla nokta bulutu, mesh üçgeni ve mesh tepe noktası (vertex) oluşturabilmekte bu özellikleri ile tünel gibi büyük boyutlu objelerin hacim hesaplamaları daha sağlıklı yaplabilmektedir.

Yüksek çözünürlüklü yoğun verilerden oluşan lazer tarama verilerinin işlenmesi, birleştirilmesi, 
yönetilmesi için geliştirilen birçok ticari yazılım mevcuttur. Ancak karmaşık problemlerin çözümü için tek bir yazılım yeterli olmayabilir. Ayrıca tez kapsamında ele alınan yersel lazer tarama verilerini değerlendirme yazılımları ile ilgili olarak FaroScene yazılımı JRC yazılımına kıyasla daha kolay ve hızlı veri işlemektedir. $\mathrm{Bu}$ özelikler deneyimsiz kullanıcılar için oldukça avantaj sağlamaktadır. JRC 3D Reconstructor yazılımının ise daha profesyonel kullanıcılara hitap etmektedir. Bu yazılım Faro Scene'in aksine çok daha fazla parametre içermesi, sayı sınırı olmadan nokta bulutu ve mesh üçgenleri oluşturması, oldukça çeşitli nokta bulutu ve mesh üretme ve düzenleme komutlarını karşılaması ve birçok geometrik uygulamaları desteklemesi bu yazılımın en güçlü $3 \mathrm{~B}$ modelleme yazılımları arasında yer almasını sağlamaktadır. Çalışma kapsamında farklı uygulamaları değerlendirmek için ele alınan veri işleme ve değerlendirme yazılımları 3B modellerde sinırlanmamakta, bu modellerden CAD ve CBS yazılımları ile hem vektör hem de raster verileri çıkarılabilmektedir.

\section{KAYNAKÇA}

Beg, R. A. (2018). Kilistra (Gökyurt) Antik Kenti yapılarının yersel lazer tarama ve insansız hava aracı tekniği ile modellenmesi, Yüksek Lisans Tezi, Selçuk Üniversitesi, Fen Bilimleri Enstitüsü

Karasaka, L. (2012). Mobil Yersel Lazer Tarama Sistemlerinin Fotogrametrik Rölöve Projelerinde Kullanılabilirliği Üzerine Bir Çalışma, Publisher.Pages.

Kushwaha, S. K. P., Dayal, K. R., Raghavendra, S., Pande, H., Tiwari, P. S., Agrawal, S., \& Srivastava, S. K. (2020). 3D Digital Documentation of a Cultural Heritage Site Using Terrestrial Laser Scanner-A Case Study. In Applications of Geomatics in Civil Engineering (pp. 49-58). Springer, Singapore.
Perc, M. N., \& Topolšek, D. (2020). Using the scanners and drone for comparison of point cloud accuracy at traffic accident analysis. Accident Analysis \& Prevention, 135, 105391.

Reshetyuk, Y., 2006, Investigation and calibration of pulsed time-of- flight terrestrial laser scanners, PhD Thesis, Royal Institute of Technology (KTH), Stockholm, 1-55

Scherer, M., (2004. Intelligent tacheometry with integrated image processing instead of 3D laser scanning? In Proceedings of INGEO 2004 and FIG Regional Central and Eastern European Conference on Engineering Surveying, Bratislava, Slovakia, November $11-13$.

Van Genechten, B. (2008). "Theory and Practice on Terrestrial Laser Scanning: Training Material Based on Practical Applications."

Vosselman, G. ve Maas, H.-G. (2010). Airborne and Terrestrial Laser Scanning. CRC.

Yılmaz, H. M. ve Yakar, M. (2006). "Yersel Lazer Tarama Teknolojisi." Yapı Teknolojileri Elektronik Dergisi 2(2): 43-48.

Yakar, M. (2011). Using close range photogrammetry to measure the position of inaccessible geological features. In Experimental Techniques, 35 (1), 54-59.

Wieczorek, T., Przyłucki, R., Lisok, J., \& Smagór, A. (2018). Analysis of the Accuracy of Crime Scene Mapping Using 3D Laser Scanners. In International Workshop on Modeling Social Media (pp. 406-415). Springer, Cham.

URL5:http://www.gexcel.homeip.net/Reconstructo r/R_Manual/R_Manual_EN.pdf.

URL8:http://www.3dreshaper.com/images/brochu res/BeginnersGuide_EN.pdf 